\title{
Algunas reflexiones sobre el arte rupestre, a través de dos fragmentos impresos de la cueva de Chaves (Huesca)
}

\author{
Vicente BaLdellou
}

A la hora de empezar a redactar este trabajo, no puedo dejar de recordar que fue precisamente el Profesor Ripoll el que me inició en el apasionante mundo del Arte Rupestre. Las primeras clases que recibí sobre el tema fueron las suyas y puedo decir, sin riesgos de caer ya en la sospecha del halago fácil o interesado, que sirvieron no sólo para hacer más sólida mi formación universitaria, sino que fueron también el vehículo inoculador que introdujo en mí un creciente interés - "gusanillo» en términos menos grandilocuentes- por las pinturas prehistóricas en sus más variadas facetas. Posteriormente, mi propia trayectoria profesional me ha llevado al contacto directo y continuado con diversas estaciones pintadas, en una relación de amor y odio que no es ajena a ningún arqueólogo profesional, pero quiero dejar constancia aquí que el inicio de dicha relación tiene mucho que ver con el Dr. Ripoll y con el entusiasmo que supo imprimir a sus lecciones.

Aunque el título de este trabajo hace referencia a dos fragmentos de alfarería impresa aparecidos en los niveles del Neolítico Antiguo de la Cueva de Chaves (Bastaras, Huesca), en realidad ambos restos cerámicos sólo sirven de introducción —o más bien de pretexto- para una serie de consideraciones hechas a vuela pluma sobre algunos aspectos que atañen a las manifestaciones rupestres en general, ya que la nimie- 
dad de los mismos no justificaría el dedicar todo un artículo a su comentario.

Los fragmentos en cuestión fueron recuperados en las campañas de excavación llevadas a cabo en los años 1984 y 1988, cuyos resultados se mantienen todavía inéditos como monografía, aunque se hayan redactado algunos estudios referidos a determinadas cuestiones concretas (Baldellou y Utrilla 1985; Baldellou y Rodanés, en prensa). Sí, se han publicado otros artículos que tratan de las dos primeras campañas arqueológicas efectuadas en la cavidad (Baldellou 1976; Baldellou, Castán, Castaños, Cava y Maya 1985), pudiéndose considerar todavía vigentes al no haberse producido contradicciones con respecto a ellos en las excavaciones más recientes.

Las piezas que nos ocupan, pese a su aparición anacrónica y producida en dos sectores diferentes pero próximos, parecen pertenecer a la misma vasija y presentan una ornamentación impresa ejecutada mediante un utensilio dentado que da lugar a unas improntas similares a las cardiales (fig. 1):

1. Fragmento de pasta de color marrón-anaranjado, con desgrasante pequeño a base de granitos de cuarzo, superficie alisada y buena cocción. Presenta un cordón en relieve sobre el que corre una banda horizontal formada por una serie de impresiones verticales; delimitando el mencionado cordón, por arriba y por abajo, pueden observarse sendas líneas de impresiones horizontales. En la parte inferior del cordón se hace patente un motivo incompleto constituido por dos franjas oblicuas convergentes en ángulo, formadas cada una de ellas por dos lineas impresas que flanquean a ambos lados un grupo de tres suaves incisiones centrales. Procede del Nivel lb, es decir, del Neolítico I o cardial pleno, enteramente asimilable al Nivel llb. de las campañas ya publicadas.

2. Fragmento de idénticas características a las mencionadas en el n. ${ }^{\circ} 1$, aunque su coloración esté ennegrecida por la acción del fuego. La zona conservada por debajo del cordón tiene una superficie muy limitada, pero permite distinguir, a la izquierda una serie de tres incisiones oblicuas y muy poco profundas, que entran en contacto con la línea horizontal de impresiones que delimita el lado inferior de la prominencia; junto a ella, existe otra banda oblicua que corre en sentido contrario y que está configurada por dos líneas impresas a uno y otro lado y dos suaves incisiones centrales. Ambas franjas, aunque tangenciales, no llegan a formar un ángulo. A la derecha, restan visibles dos nuevas líneas oblicuas, una de ellas impresa e incisa la segunda. Fue hallado en una zona de con- 

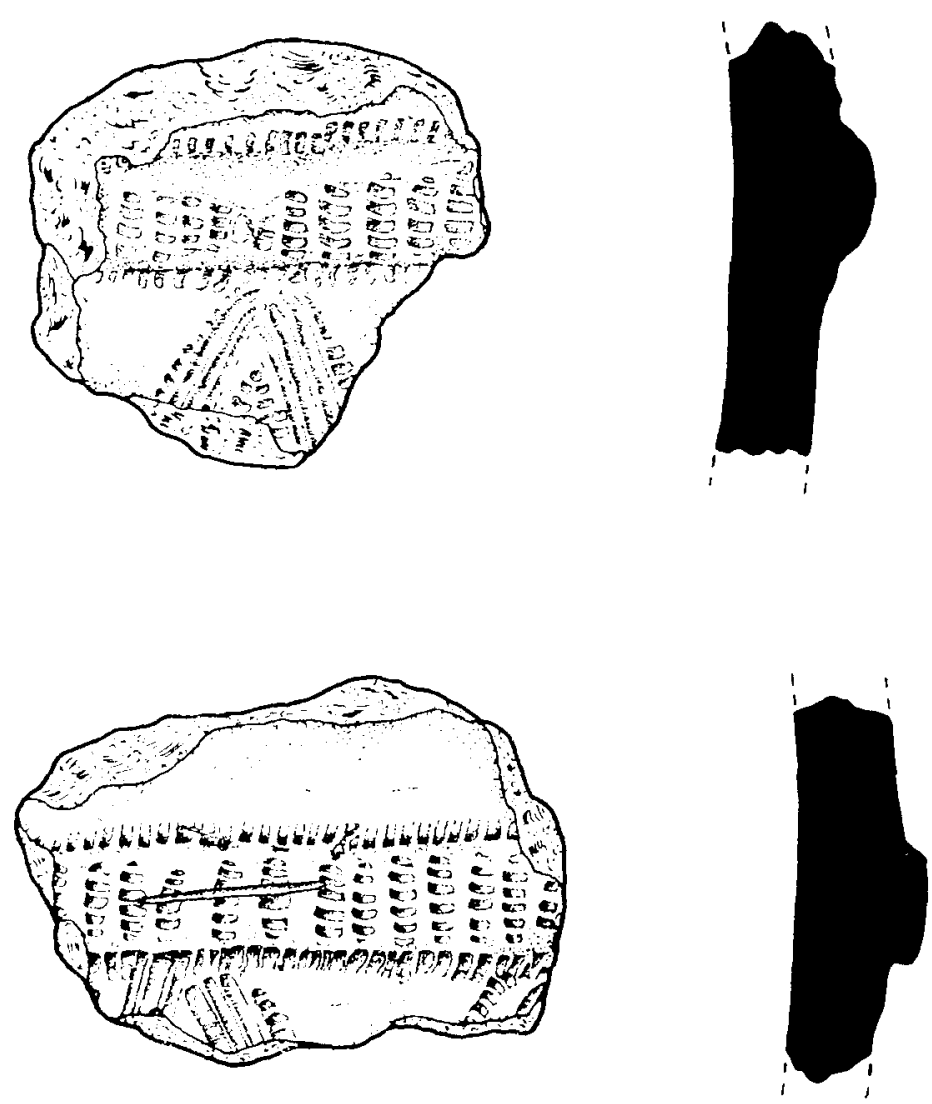

Fig. 1. Fragmentos impresos de la Cueva de Chaves (Huesca). 
tacto entre el Nivel $\mathrm{l}$ y el $\mathrm{lb}$, en un sector afectado parcialmente por remociones modernas.

Quiero hacer constar que los dos fragmentos descritos son, por sí solos, muy poco significativos $y$, como ya he dicho, inducen a pocos comentarios. Sus escasas dimensiones y su carácter incompleto no permiten suponer cómo sería el esquema original y ni siquiera estoy en condiciones de asegurar que la orientación que se muestra en la ilustración sea la correcta, es decir, que cabe en lo posible que se hayan dibujado cabeza abajo. La verdad es que no se les hubiera asignado una mayor relevancia de no haberse producido por mi parte la lectura del interesantísimo trabajo publicado por Bernat Martí y Mauro S. Hernández; a raíz de la exposición celebrada en Valencia con el titulo de «El Neolitic Valencià. Els primers agricultors i ramaders" y bajo los auspicios del "Servei d'Investigació Prehistòrica" (SIP) de la Diputación Provincial de la capital levantina (Martí y Hernández 1988).

La citada obra produjo una profunda impresión en mí y, a fuer de ser sincero, debo reconocer que esperaba una mínima oportunidad para glosar algunas observaciones propias a la misma. Dicha oportunidad me la brindaron los dos fragmentos de la Cueva de Chaves, gracias a una lejana similitud que ambos podrían guardar con otros materiales - mucho más grandes y más completos- que Martí y Hernández dan a conocer en su trabajo. El fragmento 1 se asemeja a alguno de los que se interpretan como cabezas de antropomorfo, mientras que el número dos recuerda vagamente lo que podrian ser unos dedos o manos (Martí y Hernández 1988: figs. 5, 6 y 7, pp. 56-59). Repito una vez más que tales inferencias son completamente arbitrarias y que carecen de todo fundamento, pero me sirven como excusa para lo que voy a exponer a continuación.

La única semejanza segura que se puede establecer entre los restos arqueológicos que aquí se presentan y los esgrimidos por Martí y Hernández se refiere a su contexto cultural, pues los valencianos se clasifican en un momento alto dentro del Neolítico Antiguo, en tanto que los oscenses se inscriben en el Neolítico inicial de Chaves, bien datado a través de numerosas fechaciones que lo sitúan en la primera mitad del $\mathrm{V}$ milenio (Baldellou y Utrilla, 1985). Por demás, siguiendo siempre con las razones expuestas por Marti y Hernández, los objetos cerámicos levantinos pertenecerían a unas sociedades neolíticas plenamente integradas en las nuevas directrices económicas, las cuales aceptarían sin vacilaciones el apelativo de «neolítico plenos", o "neolíticos puros» si adoptamos 
el que les da Fortea. Del mismo modo, el asentamiento habitacional de Chaves revela una conducta de sustento propia de un grupo completamente neolitizado y sin enraizamientos de ninguna índole que lo relacionen con los anteriores ocupantes de la gruta.

Fuera de la citada analogía, las apuntadas más arriba son mucho más dudosas y su viabilidad es a todas luces escasa, más aún cuando Martí y Hernández consideran que las decoraciones impresas y cardiales por ellos estudiadas son un reflejo sobre objetos muebles del arte parietal conocido como arte Macroesquemático ', manifestación pictórica que no ha sido jamás documentada en las comarcas altoaragonesas.

Parece evidente que los ejemplares manejados por ambos, al menos en buena medida, no dejan lugar a la duda en cuanto a su atribución a figuras antropomórficas; ahora bien, ¿hasta qué punto unas afinidades gráficas - a todas luces innegables- permiten establecer una identidad entre dos formas de expresión tan distintas como la cerámica impresa y la pintura rupestre? Repito que al formular esta pregunta no me baso en la existencia de los dos fragmentos objeto del presente comentario, en primer lugar porque pueden no guardar ninguna relación, más que su apariencia, respecto a los motivos ornamentales barajados por Marti y Hernández, y en segundo término porque su escasa entidad no autoriza a efectuar valoraciones intrínsecas que resultarian siempre exageradas y faltas de una base sólida, en realidad, lo que quiero exponer aquí emana directamente de la lectura del trabajo, anterior a la comprobación de la presencia de los fragmentos de Chaves. Por otro lado, no es mi intención rebatir nada de lo que Martí y Hernández nos sugieren en su importante obra, impecablemente estructurada, sino simplemente introducir ciertos elementos de reflexión a los que no he podido retraerme.

Al hilo de la pregunta que acabo de expresar, podría decir que, en mi opinión, las decoraciones alfareras y las representaciones rupestres encierran dos concepciones artísticas completamente diferentes; diferencias que atañen no tan sólo a los distintos soportes sobre los que se ejecutan y las técnicas propias de los dos medios de expresión, sino que inciden también en otros aspectos. Las alfarerias prehistóricas, aunque se puedan establecer matizaciones al respecto, responden en términos

' La reiteración con la que deberé hacer alusión a la obra de Martí y Hernández creo que me excusa de recurrir a la proliferación de citas. Valga a tal fin la primera de ellas. 
generales a unas necesidades utilitarias, conjetura ésta que difícilmente puede aplicarse a los covachos pintados, cuya finalidad, según las ideas más en boga, estaría en el extremo contrario de una simple y prosaica funcionalidad: los mismos autores reconocen el carácter mágico, incluso religioso, de las manifestaciones pictóricas. Otra circunstancia a tener en cuenta es el contexto, totalmente distinto y específico de cada variante artística: la cerámica aparece mayoritariamente en niveles de habitación, sea en cuevas o poblados, integrado en unos conjuntos materiales con un indudable cariz de uso cotidiano; las pinturas, por contra, se ubican en cavidades que parecen no haber sido ocupadas o que, si lo han sido, no suelen presentar nexos claros entre sus restos habitacionales y sus representaciones parietales. Con ello, pienso que se pone en evidencia una discrepancia esencial entre ambas expresiones artísticas y esto es lo que me pone cuesta arriba aceptar su hipotética identificación más allá de las meras coincidencias formales.

Martí y Hernández, para obviar este problema, dudan de la finalidad estrictamente funcional de algunos ejemplares alfareros, pero creo sinceramente que faltan los razonamientos categóricos para apoyar tal aseveración. En Arqueología, el destino concreto de los objetos recuperados en las excavaciones se supone según el entorno en que han sido hallados y la utilización que, por sus características, puede atribuírseles. Las cerámicas encierran pocos enigmas en cuanto a su uso y, siendo estrictos en el análisis, sólo las que corresponden a un conjunto funerario pueden poseer un sentido que exceda al simple utilitarismo. Las decoraciones cardiales e impresas valencianas, ciertamente ricas, barrocas y bien elaboradas, provienen todas ellas de niveles de habitación, aparecen mezcladas con otras piezas de uso normal y únicamente se diferencian de las de otros yacimientos de índole similar por la cuidada ejecución, por la profusión barroquizante de sus motivos ornamentales y por la notable variabilidad y originalidad de los mismos. Opino que basar su carácter excepcional en estas peculiaridades decorativas resulta a todas luces arriesgado, y más aún en la región valenciano-alicantina, donde la ingente cantidad de cerámica excelentemente ornamentadas procedentes de Or y Sarsa hace difícil pensar en otra finalidad que no sea precisamente la utilitaria. De otro modo, las vasijas de naturaleza distinta - simbólica o supra-funcional- resultarian excesivamente abundantes, demasiado para que su misma copiosidad no les hiciera perder la cualidad de extraordinarias.

Desde otro punto de vista, el arte Macroesquemático y las cerámicas cardiales presentan otras cuestiones que complican su interconexión. El 
primero constituye una manifestación artística hasta ahora muy limitada, tanto en lo tocante a su dispersión geográfica, como en lo que se refiere, al parecer, a sus connotaciones culturales. Cabe en lo posible que futuros descubrimientos amplíen el panorama en que se mueve actualmente dicho estilo pictórico, pero hoy por hoy su radio de acción queda restringido o algunas comarcas alicantinas. Las alfarerías cardiales, por el contrario, conocen un marco de difusión infinitamente mayor y se extienden por múltiples sectores en los que resulta inviable ponerlas en relación con una corriente artística tan especifica como la de las pinturas macroesquemáticas. ¿Es válido explicar esta disfunción a través de la singularidad del Neolítico con cerámicas impresas de las tierras levantinas? ¿Es esta particularidad la que justifica la existencia de un arte muy personalizado, exclusivo de los neolíticos cardiales de dicha área? Personalmente pienso que ésta es una teoria escasamente defendible, pues las anomalías de los ajuares valencianos tampoco son tan profundas respecto a los de otros círculos culturales material y cronológicamente paralelos y pueden responder simplemente a un sentido estético, desarrollado en mayor o menor medida según el lugar concreto en que nos encontremos.

Los antropomorfos en actitud de orantes que se han identificado en las ornamentaciones impresas valencianas han sido los que han levantado la liebre. Efectivamente, guardan un indubitable parecido con los macroesquemáticos, pero quizás esta semejanza no sea suficiente para proponer una imbricación total entre unas y otras figuraciones. Habria que plantearse otros aspectos accesorios para reforzar tal imbricación. Primeramente, hay que señalar que las representaciones de orantes no son en absoluto desconocidas en diversas fases prehistóricas $\mathrm{y}$ en diversos ámbitos culturales $\mathrm{y}$, en verdad, todas ellas guardan cierta similitud fundamentada en la posición levantada de los brazos. En el seno de una sociedades sometidas a un, tal vez, mal llamado primitivismo o, quizás mejor, a una civilización tecnológicamente poco avanzada, las coincidencias materiales son relativamente frecuentes y pueden implicar asímismo a determinadas soluciones formales en las apariencias artísticas. Los antropomorfos del arte Macroesquemático no constituyen el único tema de sus pinturas, pero sí ha sido el único que ha servido para establecer la hipotética relación entre las manifestaciones pictóricas y las decoraciones impresas, pues habrá que reconocer que sus otros componentes temáticos no son tan fácilmente asimilables a las decoraciones cerámicas. 
Si realmente hubiera una identificación absoluta entre lo macroesquemático y lo cardial: ¿no habría otras concomitancias más extensas?, ¿no habría una simbiosis mayor entre los motivos pintados y los impresos? Los antropomorfos que aparecen en las vasijas neoliticas representan un índice minoritario frente a los esquemas ornamentales de otro tipo, los cuales, aunque tal vez en otro nivel de calidad y elaboración, son comunes también a otros focos del Neolítico Antiguo. ¿Por qué no aparecen en las cuevas motivos tan característicos como los zig-zags, las guirnaldas, las líneas oblicuas paralelas, etc.? ¿Por qué no aparecen en las cerámicas esquemas tan típicos como los serpentiformes? ¿Por qué el tema central del arte macroesquemático, la figura humana, es tan minoritario en las alfarerías? ¿Por qué, en fin, el arte Macroesquemático muestra un desarrollo tan acusadamente vertical -salvo algunas excepciones como la Sarga-, mientras que en las cerámicas impresas tienen tanta importancia los diseños horizontales? Podrá aducirse que estamos ante dos formas de expresión totalmente distintas, con unas técnicas propias de cada una de ellas, pero tal argumento, tal y como he intentado exponer más arriba, puede vale también para poner en duda la identificación entre dos concepciones artísticas tan dispares.

Aparte de lo tratado hasta ahora, emanado de los dos fragmentos que he querido presentar aqui por su posible incidencia en las cuestiones tratadas por Martí y Hernández en su publicación, quisiera alargarme un poco más para comentar otros asuntos que ambos autores despliegan en su obra y que conciernen a la correlación de las cerámicas neolíticas valencianas con otros estilos pictóricos rupestres.

Efectivamente, una vez sentada la cronología del arte Macroesquemático en el Neolítico Antiguo, los dos investigadores, por medio de nuevas correspondencias entre lo pintado y lo impreso, se basan en otros paralelos muebles para confirmar que el Arte Levantino es más tardio que el anterior, posterioridad relativa ya puesta de manifiesto en las superposiciones detectadas en la Sarga y en el Barranc de Benialí. Manejando dos fragmentos recuperados en Coveta de L'Or, con figuraciones animalísticas de carácter naturalista y datados en una fase avanzada dentro del Neolítico Antiguo (finales del $V$ milenio), atribuyen al Arte Levantino una fechación similar $y$, por lo tanto, subsiguiente al momento inicial de los asentamientos neolíticos.

Aunque estoy completamente de acuerdo en lo tocante a las cronologías relativas de ambos artes (las estratigrafías cromáticas parecen incuestionables), no me es posible mostrarme tan conforme con los términos 
absolutos de la filiación temporal; en primer lugar porque ya he expresado mis dudas en referencia a la validez de las comparaciones entre la cerámica y el arte rupestre (valgan mis elucubraciones anteriores al respecto) y, como segunda providencia, porque también encuentro ciertas disonancias que no puedo por menos que tener en consideración.

Desde luego, no voy a ser yo el que proponga ahora para el Arte Levantino un encuadre cronológico distinto al formulado por Marti y Hernández, ya que me faltan las premisas necesarias para ello, pero tampoco veo que las utilizadas por los dos autores resulten terminantes, y por ende, irrefutables.

Hace ya más de veinte años, el Prof. Ripoll sugeria las concurrencias que se registraban si se superponían los mapas de distribución del Arte Levantino y el de las cerámicas cardiales (Ripoll 1968), concurrencias que hasta ahora no se han visto desmentidas, sino, por el contrario, reafirmadas en las respectivas ampliaciones que los descubrimientos más recientes han dictado. Tal sería el caso de la provincia de Huesca, donde después de localizarse el importante yacimiento neolítico de la Cueva de Chaves, no tardaron en aparecer manifestaciones pictóricas naturalistas de indole levantina en sus alrededores próximos (Baldellou 1984 y 1986). En consecuencia, podemos decir que las estaciones del Neolítico Antiguo con alfarerías impresas y cardiales coinciden "grosso modo" con los mismos territorios en los que se da un tipo de estilo parietal en concreto: el Arte Levantino. En las comarcas valencianas ocurre 10 mismo, aunque en algunas pocas de ellas se hayan documentado unas manifestaciones pictóricas tan personalizadas como se nos muestran hoy las macroesquemáticas, en extremo limitadas por el momento tanto a causa de su restringida distribución geográfica, como en razón de los caracteres formales que les son específicos. Es decir, si ensanchamos nuestro punto de mira para abarcar una visión de conjunto del Neolítico Antiguo del Mediterráneo peninsular, el Arte Macroesquemático pierde entidad y cede el protagonismo en aras de otro estilo rupestre más extenso, más vigoroso y, en términos generales, coincidente con el área de dispersión de las cerámicas cardiales: el Arte Levantino, mayoritario en grado sumo y especialmente en el propio Pais Valenciano.

Si la relación entre las pinturas rupestres y las decoraciones cerámicas existe. ¿No resulta un poco incongruente que el arte más extendido de la zona, el cual parece que, al menos en parte, es contemporáneo a las ornamentaciones cardiales, sea precisamente el que menos paralelos muebles nos ofrezca?; para fundamentar su atribución cronológica, Martí y Hernández manejan única y exclusivamente dos 
fragmentos, cifra todavía más minoritaria que la que nos brindaban las figuras antropomórficas y que, a mi entender, dota a ambas piezas de un tinte de excepcionalidad que, expresamente por ello, los puede invalidar hasta cierto punto para ser usados como elementos comparativos, pues deberemos convenir que su naturaleza es escasamente representativa y que su significación resulta un tanto difusa por su misma normalidad.

Los otros fragmentos que se barajan para buscar otros nexos de unión entre lo cardial y lo levantino son, en mi opinión, mucho más dudosos, sobre todo la hipotética escena de danza (fig. 18 y lam. XIlb), con una serie de antropomorfos cuya configuración gráfica se aproxima en gran manera a la de las representaciones humanas que se consideran asimilables al Arte Macroesquemático y que han sido utilizadas anteriormente como paralelos de esta corriente artística.

Es asimismo a través de otro lote de cerámicas impresas y cardiales que Martí y Hernández establecen una datación concreta para el Arte Esquemático, datación que arrancaría desde los inicios del Neolítico Antiguo, al menos que algunos de los temas que son propios del citado estilo pictórico, y que, en conclusión, resultaria más elevada que la designada para el Arte Levantino, aunque ambas tendencias rupestres llegarian a ser contemporáneas en una fase más avanzada dentro del Neolítico de las cerámicas impresas.

Personalmente, a pesar de la ausencia de datos categóricos y seguros al respecto, siempre he pensado que podía aceptarse un origen para el Arte Esquemático que fuera completamente independiente del Arte Levantino y que dicho origen resultaria tanto o más antiguo que el atribuido a este último, pero haciendo la precisión de que tal hipótesis podría ser válida para las regiones en las que los esquematismos se desarrollaban sin interferencias, es decir, donde representan desde un principio las manifestaciones pictóricas exclusivas de sus cavidades (S. y S.E. peninsulares). En las zonas donde conviven lo naturalista y lo esquemático la cuestión no se nos aparece de modo tan claro: en realidad, los palimsestos apuntan, la mayoría de las veces, a la posterioridad de lo segundo en relación a lo primero, posterioridad sólo puesta en entredicho en el Barranc de la Palla de Tormos (Hernández y Segura 1985: 45-47), circunstancia por ahora excepcional frente a los múltiples casos en los que la estratigrafía cromática pone de manifiesto una superposición inversa. Creo que se ha demostrado en muchas ocasiones que la valoración excesiva de los hechos anómalos entraña indudables riesgos y pienso que, hoy por hoy, la excepción a la regla que significa el Barranc de la Palla no puede echar por tierra los otros ejemplos conocidos 
- más numerosos sin duda - en los que el Arte Levantino subyace al Esquemático.

Tampoco veo demasiado palmaria la posibilidad de una coetaneidad absoluta entre ambos estilos: en la comarca donde he centrado últimamente mis estudios - el río Vero (Huesca) - tenemos documentadas pinturas naturalistas y pinturas esquemáticas y las superposiciones, aunque raras, indican que estas últimas se ubican por encima de las levantinas. Además, la existencia de una serie de figuras que se podrían llamar "subesquemáticas" o "semi-naturalistas" -ninguno de los dos términos me parece muy apropiado- podrian constituir un estadio intermedio entre las dos tendencias artísticas. En efecto, se trata de unos diseños que muestran un avanzado grado de estilización que los aproxima en buena medida a los esquematismos, pero que conservan todavia determinadas precisiones somáticas que los separan de la elementalidad sintética de las representaciones pintadas ya enteramente esquemáticas. Por otro lado, parece como si el Arte Esquemático del río Vero tuviera ciertos lazos de unión con lo naturalista, perdiendo parte de su contenido conceptual, esotérico o codificado, en aras de un mayor contenido descriptivo que pudiera tener conexión con las tradiciones levantinas. No hay motivos para dudar de lo que nos muestran las superposiciones, dando la impresión, además, de que no existe solución de continuidad entre el Arte Levantino, más antiguo, y el Arte Esquemático.

A través del mero análisis formal de las pinturas del río Vero se pone en evidencia una dualidad estilística cierta y dicha dualidad no puede explicarse satisfactoriamente si no es por medio de una cronologia diferente para cada una de las corrientes pictóricas. El criterio geográfico, aplicado en otras áreas para establecer una distinción de índole cultural o artística, pierde validez en una comarca tan reducida como la que es objeto de nuestros trabajos $(15 \times 15 \mathrm{~km}$. de superficie): en el Vero se comparte un mismo territorio y parece en principio poco factible imaginar, en una zona de límites tan restringidos, la presencia de dos tipos de sociedades contemporáneas que pintarian en los mismos parajes e incluso en los mismos covachos, provistas cada una de ellas de una concepción artística propia y de unas técnicas expresivas opuestas a las de sus vecinos y coetáneos.

Lógicamente, estas consideraciones teóricas se refieren exclusivamente a un sector especifico y tal vez no sean extrapolables a otras zonas como la valenciana, pero pueden resultar útiles para evitar gene- 
ralizaciones no siempre bien fundamentadas. Según la cronología emanada de los fragmentos impresos y cardiales de Or y Sarsa con elementos esquemáticos, la zona levantina se erigiría como la que nos ofrece la cronología más antigua para determinados temas del Arte Esquemático, antigüedad que sobrepasaria la hasta ahora establecida en las comarcas andaluzas que se consideraban como focos primarios de tales corrientes pictóricas y cuyos paralelos muebles no parecen ir más allá del Neolítico Medio.

La cuestión es que mientras la región andaluza, por la profusión, variedad y riqueza de sus manifestaciones esquemáticas, se amolda bien a las características que debiera ostentar un centro original de un arte de cualquier clase, no ocurre los mismo en las tierras levantinas, cuyo Arte Esquemático, pese a su reciente progresión en cuanto a la localización de estaciones que le son propias, es todavía minoritario con respecto al Arte Levantino, muestra una escasa variabilidad temática y presenta, en conjunto, un cariz general más adecuado a un núcleo marginal y poco desarrollado que a un foco original de considerable potencia.

Es el Arte Levantino el que se nos muestra especialmente floreciente y poderoso en la región valenciana, por lo que, si hay que buscar para la misma una categoria de foco primigenio respecto a alguna tendencia artistica rupestre, lo normal sería hacerlo con el tipo de arte que incorpora a su denominación una clara referencia a su misma posición geográfica, y que, pese a las continuadas ampliaciones de su radio de acción, sigue conservando en las tierras levantinas su ámbito de propagación más amplio, nutrido y pujante. El hecho de que la riqueza del Arte Levantino valenciano se corresponda, como mínimo físicamente y quizás también cronológicamente, a la riqueza de las cerámicas cardiales, puede ser una casualidad o no, como también puede serlo el que en los territorios andaluces donde el Arte Esquemático es exclusivo, las ornamentaciones hechas con "cardium» se encuentren ausentes o resulten a todas luces minoritarias.

A lo largo de toda la historia de la investigación del Arte Rupestre, las dificultades a la hora de fijar una filiación cronológica, concreta para cualesquiera de los diferentes formalismos pictóricos han sido las mismas desde un principio. Con el fin de intentar solventarlas se ha recurrido a gran cantidad de métodos, entre los cuales han tenido una innegable entidad los que se basaban en el paralelismo de las pinturas con los objetos muebles y, particularmente, con los restos cerámicos. Aunque debamos reconocer que se han producido algunos avances en esta línea, 
también es cierto que no se han podido sentar unas conclusiones que sean terminantes e irrefutables. Tal vez porque determinados motivos decorativos de las alfarerias, por su propio carácter ornamental, se han venido repitiendo a lo largo de las diversas culturas y tienen, por sí solos, poco valor cronológico y comparativo y no sirven como testimonios de tales o cuales influencias, sino que pueden encerrar una simple motivación estética. Tal vez, asimismo, porque, como he procurado exponer, las producciones cerámicas tengan poco que ver con las pinturas parietales. Por una u otra causa, la verdad es que el camino andado es mucho más corto que el que aún queda por recorrer y esto contando con que no nos hayamos equivocado de ruta.

Con la lectura de la obra de Martí y Hernández se patentiza la impresión de que ahora, casi de un plumazo, buena parte de nuestros estilos pictóricos prehistóricos encuentran su explicación en las alfarerías impresas y cardiales de algunas comarcas alicantino-valencianas, las cuales permitirian precisar sus respectivas dataciones, tanto absolutas como relativas, y determinar el contexto cultural en que los mismos aparecen y se desenvuelven.

Ya he dicho más arriba que la intención que me guía al redactar este trabajo no es la de rebatir absolutamente nada de lo que nos señalan Marti y Hernández en su estudio, sino introducir meras ideas para una reflexión complementaria. No obstante, debo aceptar que me cuesta entender que las diferentes variedades estilísticas rupestres, con sus respectivas y distintas nociones pictóricas y conceptuales, encuentren su acomodo y tengan su reflejo en un contexto tan bien definido y hasta cierto punto homogéneo como es el Neolítico Antiguo con cerámicas impresas y cardiales. Dicho de otro modo, se me hace difícil comprender que una técnica de ornamentación alfarera tan específica como la de la impresión en crudo, recoja en su seno la casi totalidad de tendencias artisticas post-paleolíticas que se dan en nuestros covachos y abrigos rocosos.

Lo cardial comparte territorio con lo levantino, sólo parcialmente con lo macroesquemático y sus límites de dispersión se ven ampliamente rebasados por lo esquemático, que sitúa sus focos más ricos y variados en zonas donde las ornamentaciones de "cardium» faltan en absoluto o muestran unos índices porcentuales claramente minoritarios. A la hora de relacionar un estilo pictórico con un círculo cultural, las conclusiones saltan a la vista, pues, como ya he dicho, soy de la opinión que las cerámicas y las manifestaciones rupestres no pueden fácilmente paralelizarse, según unos criterios formalistas, por corresponder a dos 
concepciones absolutamente distintas del hacer humano. Con todo, una vez más, habrá que dar tiempo al tiempo y esperar a que el mismo dé la razón a quien la tenga.

Huesca, marzo de 1989. 


\section{BIBLIOGRAFÍA}

Baloellou, V., 1976: “Excavaciones en la Cueva de Chaves (Bastaras, Huesca)", en XIV Congreso Nacional de Arqueología, Zaragoza, 245-252.

BALdellou, V., 1984: «El Arte Levantino del río Vero (Huesca)», en Juan Cabré Aguiló (1882-1982). Encuentro de Homenaje, Institución Fernando el Católico, Zaragoza, 133-139.

BALDELLOU, V., 1986: "Dos nuevos covachos con pinturas naturalistas en el Vero (Huesca)», en Estudios en Homenaje al Dr. Antonio Beltrán Martínez, Universidad de Zaragoza, 115-133.

Baldellou, V.; Castan, A.; Castaños, P. M. ; Cava, A.; Maya J. L., 1985: "La Cueva de Chaves en Bastaras", Bolskan, 1, Huesca, 9-145.

BAldellou, V.; UtRilla, P., 1985: "Nuevas dataciones de radiocarbono en la Prehistoria oscense", Trabajos de Prehistoria, 42, Madrid, 8395.

BALDELLOU, V. y RODANES, J. M.: «Un interesante fragmento de brazalete de la Cueva de Chaves (Huesca)" en Homenaje al Dr. Juan Maluquer de Motes. Barcelona (en prensa).

Hernandez, M. S. y Segura, J. M., 1985: «Pinturas rupestres esquemáticas en las estribaciones de la Sierra de Benicadell. Vall d'Albaida (Valencia)." Valencia.

MARTI, B. y HeRnANDEZ, M. S., 1988: “El Neolític Valencià. Art rupestre i cultura material', Valencia, SIP.

RIPOLL, E., 1968: “Cuestiones en torno a la cronología del arte rupestre postpaleolítico en la Península Ibérica", en Simposio de Arte Rupestre, Barcelona, 165-192. 